\title{
Determination of location-specific solidification cracking sus- ceptibility for a mixed dissimilar alloy processed by wire-arc additive manufacturing
}

\author{
Soumya Sridar ${ }^{1}$, Noah Sargent ${ }^{1}$, Xin Wang ${ }^{1}$, Michael A Klecka ${ }^{2}$, and Wei Xiong ${ }^{1, *}$ \\ 1 Physical Metallurgy and Materials Design Laboratory, Department of Mechanical Engineering and Materi- \\ als Science, University of Pittsburgh, Pittsburgh PA, 15261, USA. \\ 2 Raytheon Technologies Research Center, 411, Silver Lane, East Hartford, CT 06108, USA \\ * Correspondence: w-xiong@outlook.com or weixiong@pitt.edu; Tel.: +1-(412) 383-8092.
}

\begin{abstract}
Solidification cracking is a major obstacle when joining dissimilar alloys using additive manufacturing. In this work, location-specific solidification cracking susceptibility has been investigated using an integrated computational materials engineering (ICME) approach for a graded alloy formed by mixing P91 steel and Inconel 740H superalloy. An alloy mixture of $26 \mathrm{wt}$.\% P91 and 74 wt.\% Inconel $740 \mathrm{H}$, with high configurational and total entropy, was fabricated using wire-arc additive manufacturing. Microstructure characterization revealed intergranular solidification cracks in the FCC matrix, which increased in length along with enrichment of $\mathrm{Nb}(\sim 27$ to 56 wt.\%) and $\mathrm{Cu}(\sim 87 \mathrm{wt} . \%)$ in the middle and top regions. DICTRA simulations to model location-specific solidification cracking susceptibility showed that the top region with the highest cooling rate (270 $\mathrm{K} / \mathrm{s}$ ) has the highest solidification cracking susceptibility in comparison with the middle and bottom regions. This is in good agreement with the experimentally observed varying crack length. From Scheil simulations, it was deduced that enrichment of $\mathrm{Nb}$ and $\mathrm{Cu}$ affected the solidification range as high as $\sim 77 \%$ in comparison with the matrix composition. The overall solidification cracking susceptibility and freezing range was highest for the $26 \mathrm{wt} . \%$ P91 alloy amongst the mixed compositions between $\mathrm{P} 91$ steel and $740 \mathrm{H}$ superalloy, proving that solidification characteristics play a major role in alloy design for additive manufacturing.
\end{abstract}

Keywords: functionally graded alloy; directed energy deposition; solidification cracking susceptibility; ICME; CALPHAD; high entropy.

\section{Introduction}

The high energy efficiency of steam power cycles in advanced ultra-supercritical power plants requires the steam temperature above $700^{\circ} \mathrm{C}$ and the steam pressure up to $35 \mathrm{MPa}$. High steam pressure and temperature require the use of materials with excellent creep and high-temperature oxidation resistance. Conventionally used ferritic-martensitic steels, such as P91 steel, can be employed only up to $650^{\circ} \mathrm{C}$ [1]. Hence, Ni-based superalloys, such as Inconel $740 \mathrm{H}$ (referred as $740 \mathrm{H}$ hereafter), were designed with high $\mathrm{Co}(\sim 20$ wt.\%) and $\mathrm{Cr}(\sim 24 \mathrm{wt} . \%)$ content to achieve superior creep properties up to $850^{\circ} \mathrm{C}$ [2]. However, $740 \mathrm{H}$ is expensive compared to the traditional $\mathrm{P} 91$ steels due to the high content of alloying elements. Therefore, P91 steels can be employed in sections with operating temperatures below $650^{\circ} \mathrm{C}$, while Inconel $740 \mathrm{H}$ can be utilized for parts operating at a higher temperature, especially, for the repairing and multifunctional purposes. This strategy involves joining P91 steel with $740 \mathrm{H}$, which is challenging because these materials possess strikingly different crystal structures and properties. This necessitates using an 
interlayer for joining these dissimilar materials which, possesses intermediate properties to ensure a smooth transition between the parent materials.

It is well known that in the high-entropy alloy composition range, there is a high chance that entropy contributions can overcome the enthalpies of compound formation and hence, avoid the formation of harmful intermetallic compounds [3]. For achieving improved creep properties, the formation of detrimental phases, such as the topologically close-packed (TCP) phases, needs to be suppressed. Alloys with multiple principal elements, rather than a single principle element, exhibit the high entropy effect by stabilizing a solid solution phase over the formation of intermetallic compounds [4-6]. The simple microstructure of multi-principal element alloys makes them an attractive candidate material for achieving superior elevated temperature properties. Therefore, exploring interlayer materials with high configurational and total entropy will be suitable for joining P91 steel and $740 \mathrm{H}$ superalloy in ultra-supercritical power plants.

Additive manufacturing ( $A M)$ is an advanced manufacturing technique that can fabricate structural parts layer by layer using 3-dimensional models [7]. It is a promising alternative for joining dissimilar materials using an interlayer or gradual composition gradient. Directed energy deposition (DED) has been used for multi-material deposition extensively [8-10]. Wire-arc additive manufacturing (WAAM) is a cost-effective DED-based technique that uses welding wire as starting material. The deposition rate of WAAM is much higher, enabling the efficient fabrication of large components. Some of the crucial parameters such as torch tilt, bead size and geometry, external magnetic field and microstructural evolution have been evaluated using physics-based models as well as key experiments to improve the WAAM process in comparison with other conventional manufacturing techniques such as machining [11-15]. The ability to fabricate large builds is beneficial for real world applications but, special attention must be given to changes in the thermal history that can lead to location-specific changes in material behavior and properties. Changes in thermal history can lead to significant changes in the as-built microstructure, residual stress, and solidification cracking susceptibility [16-18].

Solidification cracking is a common defect observed in additively manufactured parts that limits its applicability. Solidification cracks are caused by the trapping of interdendritic liquid. When liquid becomes trapped, differences in the solid and liquid density lead to shrinkage inside the mushy zone [19]. Since the grains are not firmly held together, due the presence of grain boundary liquid, the strength of the mushy zone is low. Moreover, the liquid phase fraction is not high enough towards the end of solidification to accommodate large tensile strains and the rearrangement of grains [19]. The capability of the liquid metal to fill the interdendritic region plays an important role in determining the solidification cracking susceptibility. The main factors that need to be accounted for when assessing the solidification cracking susceptibility are the freezing range, amount and distribution of liquid at the end of solidification, primary solidification phase and grain structure [20].

Several models are available in the literature for predicting the solidification cracking susceptibility of an alloy as a function of composition [21-27]. In particular, the Kou model $[19,28]$ provides a comprehensive approach for assessing the solidification cracking susceptibility for fusion welds. Such a solidification cracking model can determine the risk of solidification cracking. The Kou model relates the solidification gradient to the solidification cracking susceptibility of a material. In particular, it can directly link to the ScheilGulliver model [29], which is commonly used to predict the solidification gradient. Recently, the DICTRA (diffusion-controlled transformations) package within Thermo-Calc software has been used to model the solidification gradient by considering the effects of thermal history and kinetics [30]. Though, there are similarities between welding and AM, the Kou model has not been used extensively to evaluate the solidification cracking susceptibility for AM processes. There are only a few reports that evaluate the solidification cracking susceptibility for alloys processed using AM [17,31-34]. So far, to the best of our knowledge, there are no reports evaluating the location-specific solidification cracking susceptibility of additively manufactured alloys. 
In this work, the location-specific solidification cracking susceptibility has been evaluated for a mixed alloy with high calculated configurational and total entropy, that can potentially act as an interlayer for joining $\mathrm{P} 91$ steel and $740 \mathrm{H}$ superalloy. The mixed alloy was fabricated using WAAM and the difference in cracking behavior at various locations along the build direction has been correlated with the solidification cracking susceptibility deduced by applying the Kou model criterion. The extent of microsegregation in different locations and its effect on the solidification range has also been investigated. This work is aimed at providing a pathway to assess the feasibility of fabricating new alloys designed using the ICME (integrated computational materials engineering) approach for AM processes. Moreover, it demonstrates how an ICME-based framework can be employed to determine the location-specific solidification cracking behavior and can be correlated with the experimental observations. The main aim of this work is to establish that apart from the prediction of thermodynamic properties and microstructure, the solidification behavior also needs to be taken into account for obtaining crack-free builds successfully. In addition to that, some of the possible shortcomings that could have led to cracking is explored, which will have to be carefully evaluated for fabrication of new alloys using AM.

\section{Materials and Methods}

With the aim of identifying an alloy with highest entropy amongst the mixed compositions between $\mathrm{P} 91$ steel and $740 \mathrm{H}$ superalloy to act as an interlayer for joining the constituent materials, the total entropy for each alloy was calculated using the CALPHAD (Calculation of Phase Diagrams) approach as implemented in Thermo-Calc software. Additionally, the configurational entropy was determined for these compositions using the well-known Boltzmann equation as follows.

$$
S_{\text {config }}=\sum_{i}^{n} x_{i} \ln x_{i}
$$

where, $\mathrm{x}$ is the composition of component $\mathrm{i}$ in mole fraction and $\mathrm{n}$ is the total number of elements in the alloy system. The mixed compositions between $\mathrm{P} 91$ steel and $740 \mathrm{H}$ superalloy were determined by computing the weighted mean of the composition of each element for varying content of P91 steel (in steps of $1 \mathrm{wt} . \%$ ) and used as input for these calculations. The composition of the P91 and 740H wires (listed in Table 1) used for WAAM processing were used to find the weighted average. From the calculated entropy values for the mixed compositions, shown in Figure 1(a), it can be observed that the configurational entropy as well as the total entropy reaches a maximum at $26 \mathrm{wt} \% \mathrm{P} 91$ and hence, this composition was chosen for fabrication using WAAM. 

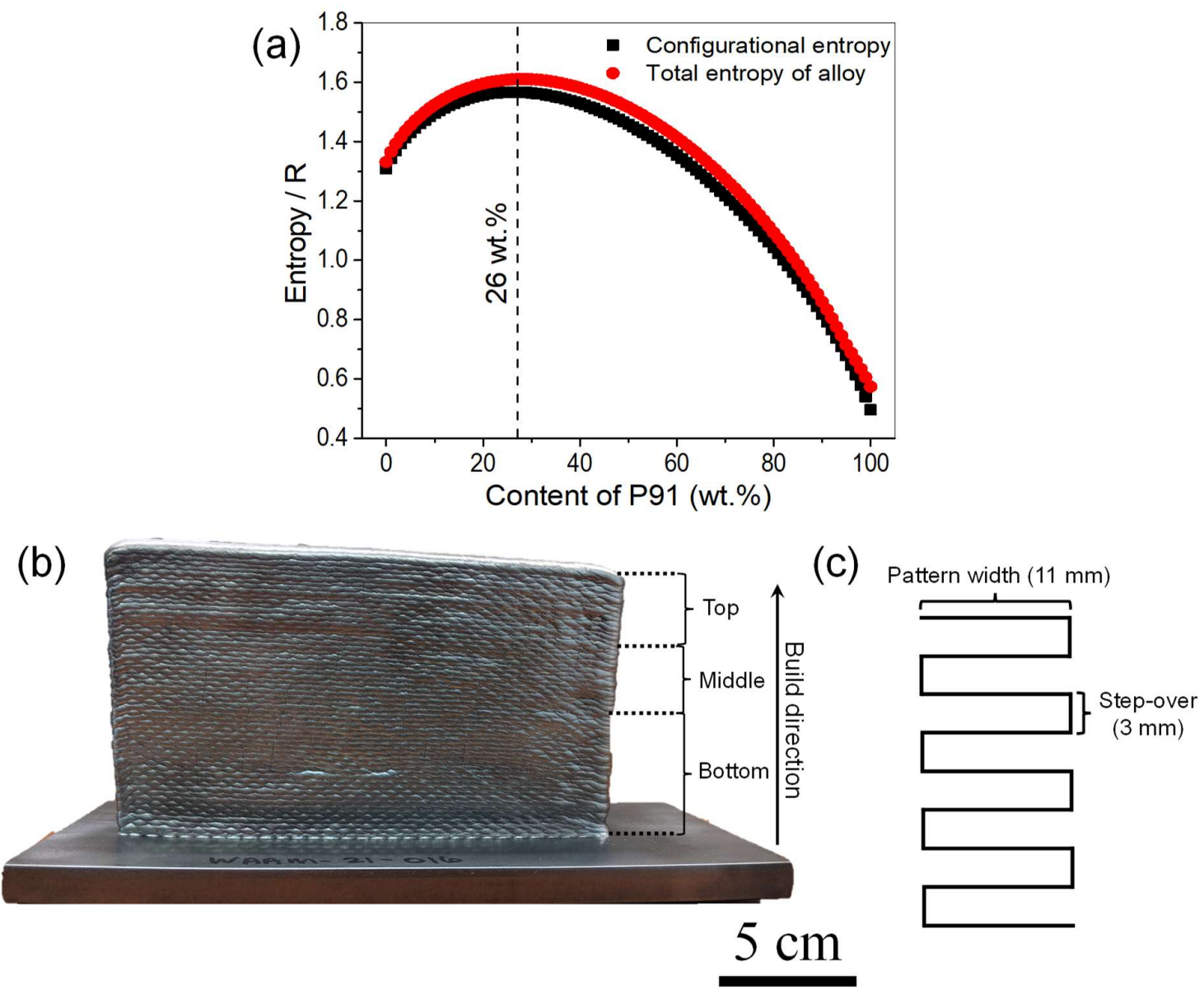

Figure 1. (a) Configurational and total entropy calculated for the mixed compositions of $\mathrm{P} 91$ steel and $740 \mathrm{H}$ superalloy showing a maximum at $26 \mathrm{wt} . \%$ P91, (b) $26 \mathrm{wt} . \%$ P91 build and (c) the printing pattern used foreach layer during fabrication of the build using WAAM.

P91 steel (ER90S-B91, manufactured by Euroweld, USA) and 740H superalloy (Special Metals Welding Products Co., USA) wires with compositions (specified by vendor) listed in Table 1 were employed for the deposition of $26 \mathrm{wt} . \%$ P91 alloy using WAAM. The diameter of the $\mathrm{P} 91$ steel and $740 \mathrm{H}$ superalloy wires were 0.9 and $1 \mathrm{~mm}$, respectively. A sample of $180 \mathrm{~mm}$ length, $11 \mathrm{~mm}$ width, and $100 \mathrm{~mm}$ height were built over a mild steel (Fe-0.165C-0.6Mn-0.225Si, wt.\%) substrate of nearly $13 \mathrm{~mm}$ thickness using a WAAM system (ABB robotic platform) with plasma torch in Raytheon Technologies Research Center (RTRC) as shown in Figure 1(b). A plasma arc welding (PAW) torch and a twin wire feeder connected to a six-axis robot were the major components of the WAAM setup. The printing parameters were selected based on an earlier design of experiments used while depositing the constituent materials, namely P91 steel and Inconel 740H superalloy. A range of conditions was deposited with different travel speeds, wire feeds, and power, until a stable melt pool was achieved based on observations and microscopy. The process parameters were selected, keeping in mind that the same conditions have to be used for the deposition of P91 steel and Inconel 740H superalloy to allow for smooth transitioning between the components while attempting for multi-material builds using WAAM.

For plasma production and shielding of PAW torch, purified Argon gas was used with a flow rate of 1.2 liter/min. Each layer was deposited in a square wave pattern with a width of $11 \mathrm{~mm}$ and step-over (spacing) of $3 \mathrm{~mm}$ (Figure 1(c)) while the overall mass deposition rate was $0.9 \mathrm{~kg} / \mathrm{hr}$. The distance between the torch and deposit was $12 \mathrm{~mm}$ and 
the wire was fed at an angle of $30^{\circ}$. In order to reach the nominal composition listed in Table 1 for $26 \mathrm{wt} . \%$ P91 alloy, the wire feed rate was maintained as $0.82 \mathrm{~m} / \mathrm{min}$ for P91 steel and $1.8 \mathrm{~m} / \mathrm{min}$ for the $740 \mathrm{H}$ superalloy. The average voltage was $20.9 \mathrm{~V}$ while the current and travel speed were varied for different layers as summarized in Table 2 . The current and travel speed are automated using the robotic motion platform whose values are prescribed by the operator for each layer. High current and low travel speed was employed for the first few layers to ensure complete adhesion with the mild steel substrate and further reduced gradually for the subsequent layers. The interpass temperature was maintained as $175^{\circ} \mathrm{C}$ i.e., each layer was cooled till $175^{\circ} \mathrm{C}$ before the deposition of the subsequent layer to reduce dilution between layers affecting the height of the build. An infrared (IR) pyrometer was used to monitor the interpass temperature during the deposition. It is to be noted that the melt pool temperature was not monitored. The temperature of the melt pool was too high to be detected using the IR camera, and the camera was blinded by the plasma arc used for deposition in the WAAM process. After each layer was deposited, the IR camera was used to monitor the temperature of the bulk part so as to ensure that the sample was below $175^{\circ} \mathrm{C}$ before beginning to deposit the subsequent layer. The interpass time for each layer was not fixed but rather dictated by the time it takes for the bulk of the sample to cool to below $175^{\circ} \mathrm{C}$.

Table 1. Composition (in wt.\%) of the $\mathrm{P} 91$ and $740 \mathrm{H}$ wires used for deposition in the WAAM process and the nominal composition (in wt.\%) of $26 \mathrm{wt.} \%$ P91 alloy.

\begin{tabular}{cccccccccccccc}
\hline \multirow{2}{*}{ Material } & \multicolumn{110}{c}{ Composition (wt.\%) } \\
\cline { 2 - 15 } & $\mathrm{Al}$ & $\mathrm{C}$ & $\mathrm{Co}$ & $\mathrm{Cr}$ & $\mathrm{Cu}$ & $\mathrm{Fe}$ & $\mathrm{Mn}$ & $\mathrm{Mo}$ & $\mathrm{Nb}$ & $\mathrm{Ni}$ & $\mathrm{Ti}$ & $\mathrm{Si}$ & $\mathrm{V}$ \\
\hline P91 & 0.003 & 0.09 & - & 9.2 & 0.03 & Bal. & 0.45 & 0.91 & 0.052 & 0.4 & - & 0.26 & 0.21 \\
$740 \mathrm{H}$ & 1.4 & 0.03 & 20.3 & 24.6 & 0.02 & 0.2 & 0.24 & 0.5 & 1.49 & Bal. & 1.5 & 0.1 & - \\
26 wt.\% P91 & 1.037 & 0.046 & 15.02 & 20.6 & 0.023 & 23.13 & 0.29 & 0.61 & 1.12 & Bal. & 1.11 & 0.14 & 0.06 \\
\hline
\end{tabular}

Table 2. Printing parameters for 26 wt. $\%$ P91 build fabricated using WAAM.

\begin{tabular}{ccc}
\hline Layer No. & Current (A) & Travel speed (mm/s) \\
\hline $26-58$ & 162 & 5 \\
$6-25$ & 166 & 5 \\
5 & 175 & 5 \\
4 & 195 & 5 \\
3 & 205 & 5 \\
2 & 215 & 4 \\
1 & 255 & 3.5 \\
\hline
\end{tabular}

The build (Figure 1(b)) fabricated using the WAAM technique was sectioned along the $\mathrm{XZ}$ plane ( $\mathrm{X}$ is the scan direction and $\mathrm{Z}$ is the build direction) with electric discharge machining (EDM, Mitsubishi MV2400S, Japan). This slice of sample was used for further location-specific analysis and the sample will be partitioned as Top, Middle and Bottom as indicated in Figure 1(b) for ease of identification. The sample was ground from 800 to 1200 grit $\mathrm{SiC}$ emery papers and further, polished using diamond ( 3 and $1 \mu \mathrm{m}$ particle size) and colloidal silica $(0.04 \mu \mathrm{m}$ particle size) suspensions to obtain a scratch-free surface with mirror finish. The cracks at different locations along the build direction were viewed in the as-polished surface using a ZEISS Sigma 500 VP scanning electron microscope (SEM) in both secondary electron (SE) and backscattered electron (BSE) modes. The composition maps were determined using Oxford Aztec energy dispersive spectroscope (EDS) attached to the SEM. To determine the nature of the cracks, electron backscattered diffraction (EBSD) was carried out using FEI Scios Dual Beam focused ion beam (FIB) - SEM equipped with EDAX Hickory EBSD system and analyzed using TSL-OIM software version 8. 
To evaluate the location-specific solidification cracking susceptibility, non-equilibrium simulations using DICTRA and Scheil modules were performed using the ThermoCalc software. The TC-API (Thermo-Calc Application Programming Interface) toolkit known as TC-Python (based on Python programming language) was mainly used for these simulations to enable batch calculations. TCNI (v8), which is the commercial multicomponent thermodynamic database and MOBNI (v4), the multicomponent mobility database were used for the simulations. In the Scheil modeling, the back diffusion due to carbon was taken into account [29]. The input compositions were obtained using EDS at various points around the cracks from different locations and the Scheil simulations were performed for 75 different points to determine the effect of segregation on the solidification range (temperature difference between liquidus and solidus).

The solidification cracking susceptibility was evaluated using the Kou criterion [19] coupled with one-dimensional DICTRA simulations. The input parameters required for the DICTRA simulations, i.e., the cell size and cooling rate, from each section of the build, as shown in Figure 1(b), were obtained by observing the microstructure under the SEM in SE mode. The samples used for SEM were etched by immersing in a solution consisting of 4.8 grams of $\mathrm{CuCl}_{2}, 4 \mathrm{~mL}$ of water, and $48 \mathrm{~mL}$ of $\mathrm{HCl}$ for nearly 25 seconds. The secondary dendrite arm spacing (SDAS) was measured from the SEM micrographs using the ImageJ software. The cell size for the DICTRA simulation for the top, middle and bottom regions was considered as half the SDAS size. In order to determine the location-specific cracking susceptibility, the cooling rate in different regions needs to be identified. Therefore, the cooling rate was determined from the SDAS using the following relation determined for Inconel 625 by Tinoco et al. [35]:

$$
\lambda=58.02 R^{-0.312}
$$

where, $\lambda$ is the SDAS, and $\mathrm{R}$ is the cooling rate. The cooling rate from different regions determined using Equation (2) was incorporated, and a linear grid with 100 points was used for these simulations. The solid fraction calculated as a function of temperature from the DICTRA simulations was used for determining the solidification cracking susceptibility using the Kou criterion by finding the maximum in the slope of the temperature vs. square root of the solid fraction curve [28]. For computing the derivative to determine the slope, a three-point central Lagrange polynomial differentiation similar to the method reported by Sargent et al. [17].

\section{Results}

\subsection{Characterization of cracks}

Figure 2 shows the SE-SEM micrographs of the cracks of varying lengths from different locations of the sample. It can be observed that the longest cracks were observed in the Top portion of the sample and the crack length decreases in the Middle region. No cracks were observed in the Bottom region of the sample. It is to be noted that cracking was observed only after deposition of the first 15 layers during the WAAM processing, although, in total, there are 58 layers to accomplish the build. The inverse pole figure (IPF), kernel average misorientation (KAM) and phase maps obtained from the cracked region in the top and middle portions of the sample using EBSD are shown in Figure 3. It is evident from the IPF map that the grain structure is columnar, and the crack is intergranular since it propagates along the grain boundary. Moreover, the grains are coarser in the middle portion since it has undergone multiple thermal cycling during the deposition in comparison with the top section of the sample. KAM represents the residual stresses qualitatively and is defined as the average misorientation around a point corresponding to a defined set of nearest neighbors [36,37]. Therefore, we applied it to gain more insight into the crack formation at locations 1 and 2. From the KAM maps (Figures 3(c) and 3(d)), it can be observed that the region around the crack has a very high misorientation angle (red 
points with $\mathrm{KAM} \sim 5^{\circ}$ and the yellow regions with $\mathrm{KAM} \sim 3-4^{\circ}$ surrounding the crack) in comparison with the surrounding matrix implying that the residual stresses are high near the cracked region. It is also evident that the grains in the top portion of the sample have higher KAM (green regions with $\mathrm{KAM} \sim 2-3^{\circ}$ ) within the grains in comparison with the Middle portions (blue regions with $\mathrm{KAM} \sim 0^{\circ}$ ) within the grains. This is because the middle portion undergoes a larger number of heating and cooling cycles that annihilates the residual stresses while the top layers are subjected to lesser thermal cycling leading to higher residual stress within the grains. From the phase maps (Figs 3(e) and 3(f)), it is evident that the 26 wt.\% P91 alloy has a single-phase FCC structure.

Figures 4 and 5 show the composition maps for the major ( $\mathrm{Ni}, \mathrm{Fe}, \mathrm{Cr}$, and $\mathrm{Co}$ ) and minor $(\mathrm{Cu}, \mathrm{Mo}, \mathrm{Nb}$, and $\mathrm{Ti})$ alloying elements from the cracked regions in the top and middle sections of the sample, respectively. The composition maps for $\mathrm{Cu}$ and $\mathrm{Nb}$ clearly show that the extent of segregation varies in different sample locations. The Cu segregation is higher in the top portion of the sample but is lower in the middle portion. Thus, it is clear that the extent of $\mathrm{Cu}$ segregation increases as the build height increases. On the other hand, $\mathrm{Nb}$ segregation is found to be more pronounced in the middle section but to a lesser extent in the top portion of the sample. Therefore, it can be inferred that the difference in length of the cracks and extent of segregation of the minor alloying elements such as $\mathrm{Cu}$ and $\mathrm{Nb}$ will lead to varying solidification cracking susceptibility along the build direction, which will be estimated using computational techniques as explained further. 


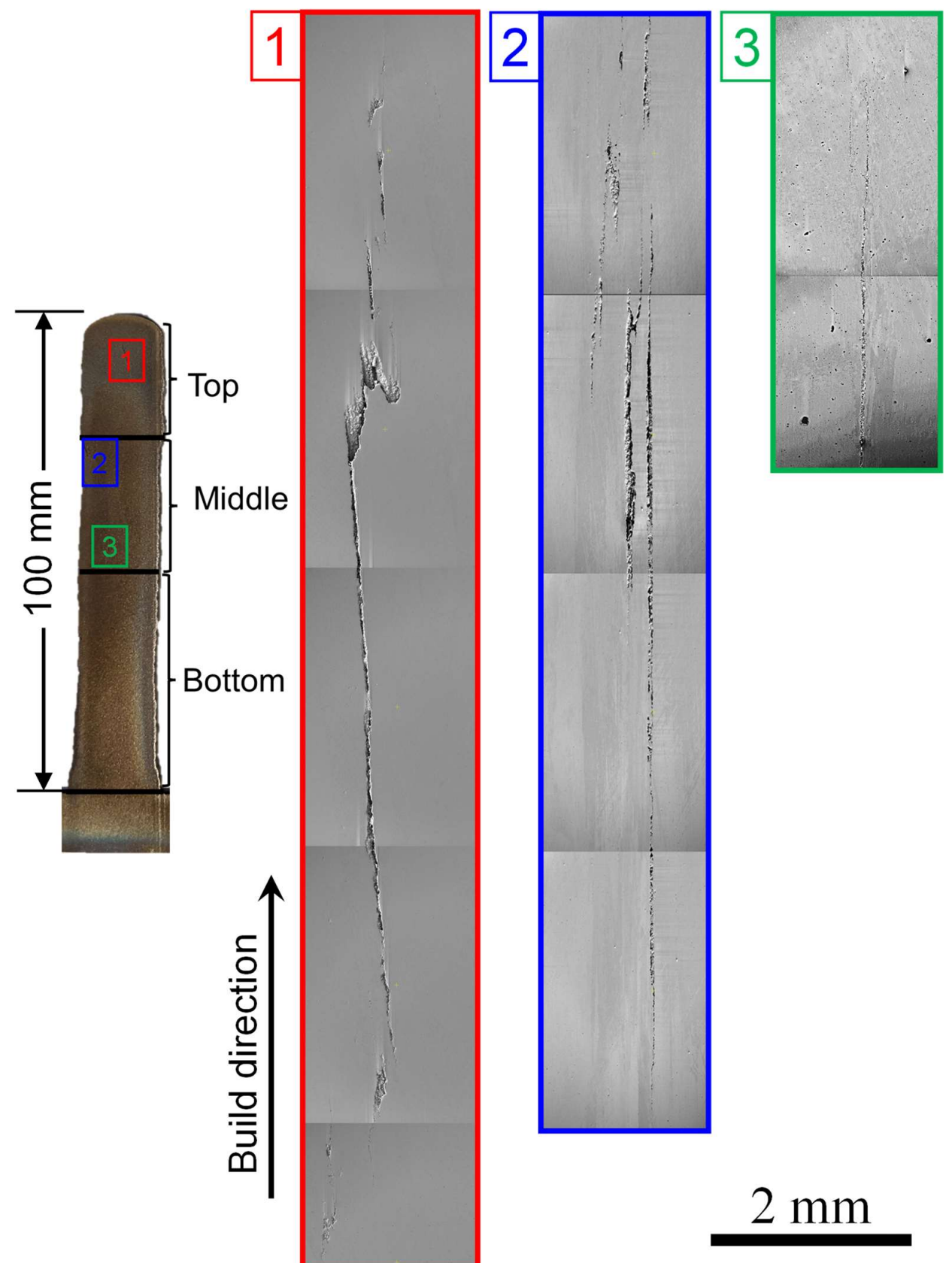

Figure 2. SE-SEM micrographs showing cracks of varying length from different locations of the 26 wt. $\%$ P91 sample along the build direction. 


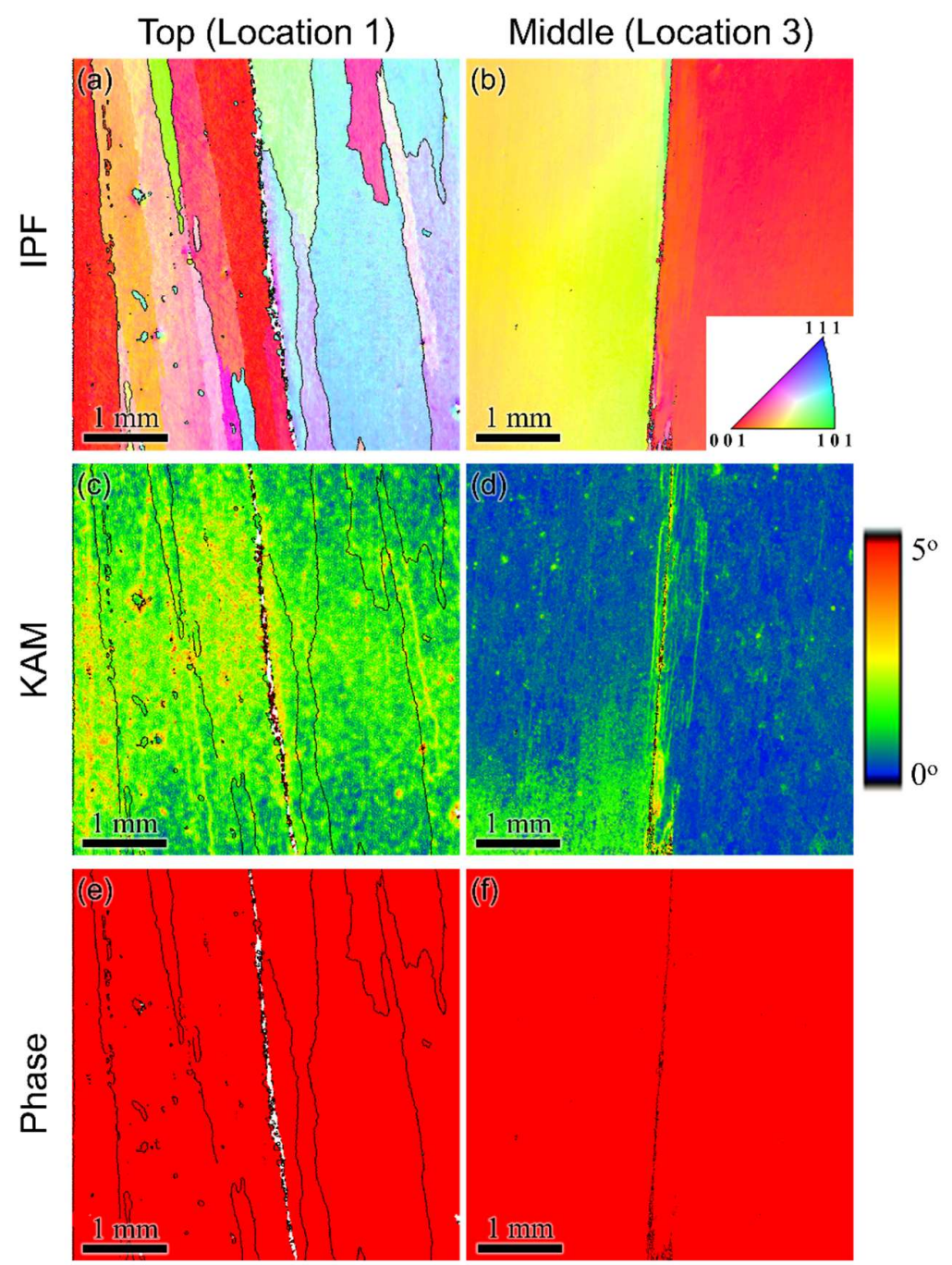

Figure 3. (a, b) IPF, (c, d) KAM and (e, f) Phase maps from Locations 1 and 3 (shown in Figure 2) from the Top and Middle sections, respectively, showing that the cracks are intergranular with high KAM around the crack. 

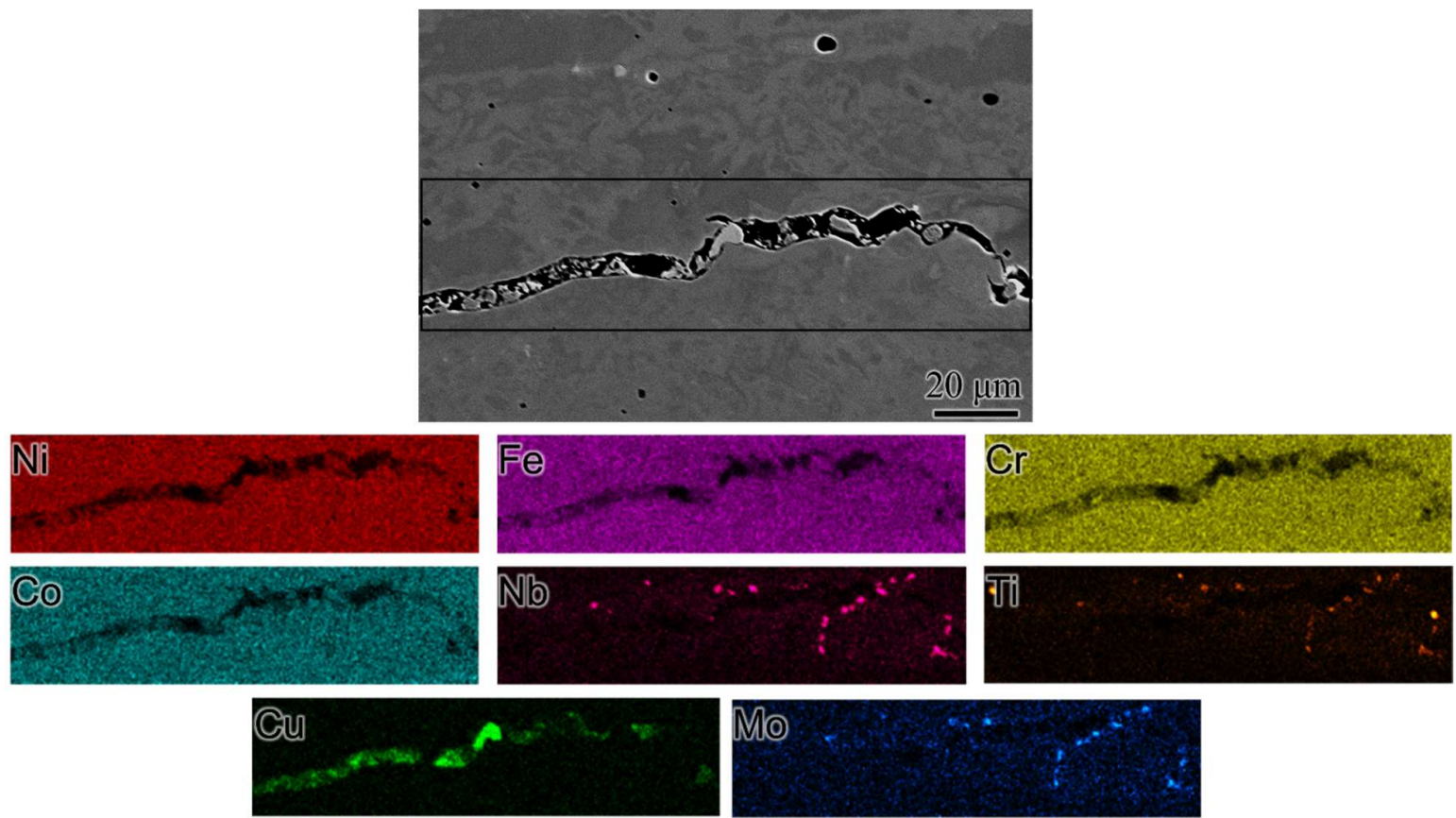

Figure 4. BSE-SEM micrograph along a crack from the Top portion (Location 1 in Figure 2) of the sample and their corresponding composition maps for major (Fe, $\mathrm{Ni}, \mathrm{Co}, \mathrm{Cr})$ and minor $(\mathrm{Nb}, \mathrm{Ti}, \mathrm{Mo}, \mathrm{Cu})$ alloying elements.

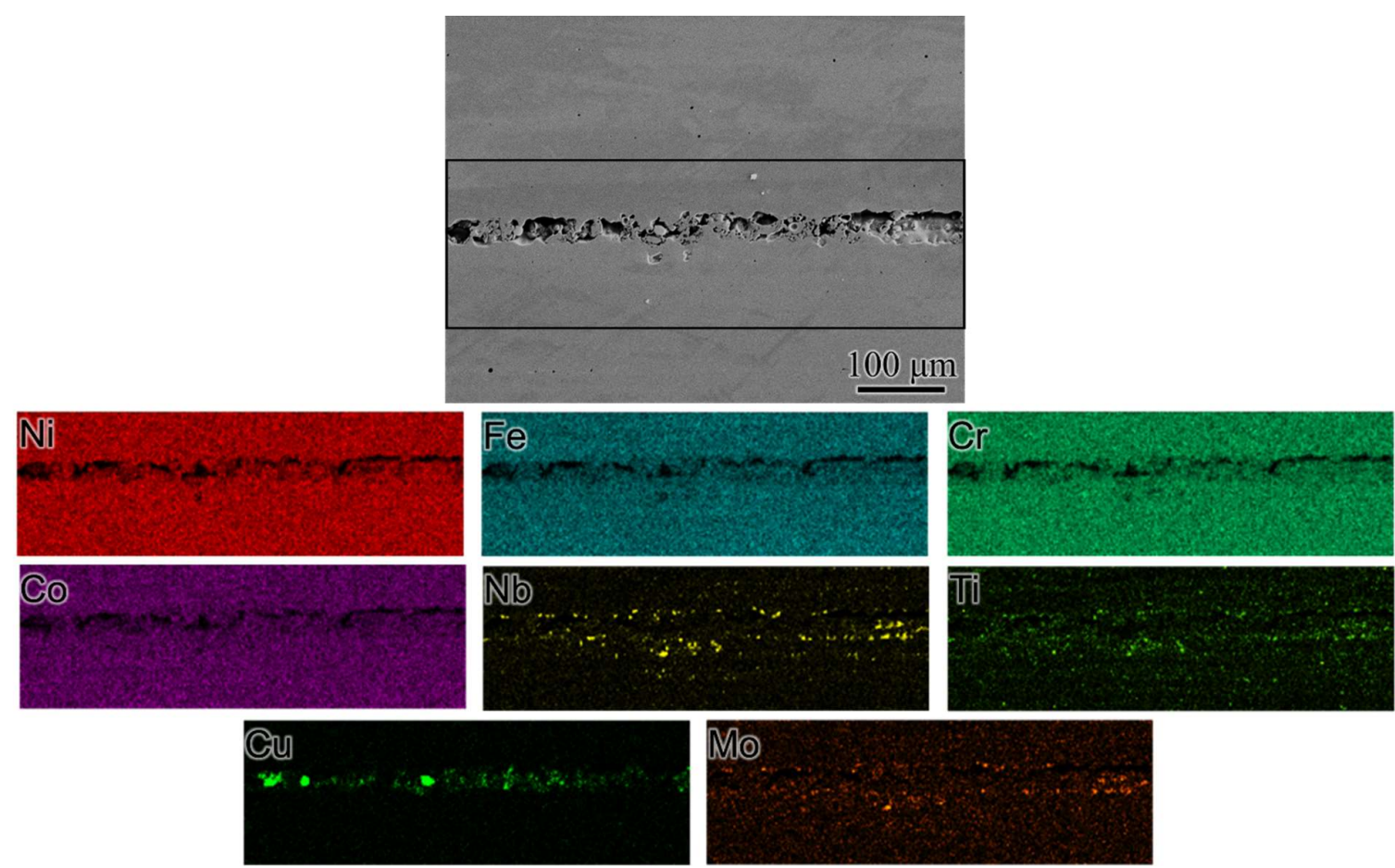

Figure 5. BSE-SEM micrograph along a crack from the Middle portion (Location 2 in Figure 2) of the sample and their corresponding composition maps for major $(\mathrm{Fe}, \mathrm{Ni}, \mathrm{Co}, \mathrm{Cr})$ and minor ( $\mathrm{Nb}, \mathrm{Ti}, \mathrm{Mo}, \mathrm{Cu})$ alloying elements. 
To estimate the location-specific solidification cracking susceptibility in the $26 \mathrm{wt} . \%$ P91 alloy processed using the WAAM technique, the Kou criterion coupled with DICTRA simulations were used [17].

The SDAS was determined from the etched microstructure of the sample, as shown in Figure 6(a). The compositions determined using EDS from different regions are listed in the table embedded in Figure 6. It can be observed that the concentration of $\mathrm{Nb}$ varies significantly in different locations. $\mathrm{Nb}$ enrichment can be observed in the interdendritic region (Point 2 in Figure 6(a)) in comparison with the dendrites (Point 1 in Figure 6(a)) including the primary and the secondary ones. However, the white precipitates found in the interdendritic region have a higher $\mathrm{Nb}$ content along with $\mathrm{Ti}$ and Mo. These precipitates correspond to the Laves phase (Point 3 in Figure 6(a)). Due to the increased enrichment of $\mathrm{Nb}$ towards the end of solidification, the Laves phase is expected to form in the interdendritic region. Moreover, Laves phase was found to be one of the solidifying phases towards the end of solidification from the Scheil solidification curve obtained for the nominal composition of $26 \mathrm{wt}$ \% P91 listed in Table 1. The SDAS calculated using the etched micrographs and the cooling rate calculated using Equation (2) are shown in Figures 6(b) and 6(c), respectively. An inverse correlation was observed between the SDAS and the cooling rate. It is to be noted that though, a constant interpass temperature $\left(175^{\circ} \mathrm{C}\right)$ was maintained during the deposition of each layer to control the bulk cooling rate, the local cooling rate was found to vary considerably leading to variation in microstructural features along the build direction. The estimated cooling rate and SDAS were used as inputs for the DICTRA simulation.

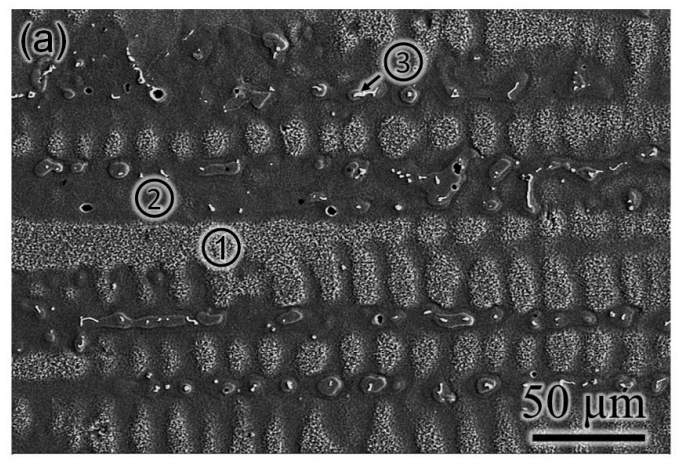

\begin{tabular}{|c|c|c|c|c|c|c|c|}
\hline \multirow{2}{*}{$\begin{array}{c}\text { Point } \\
\text { No. }\end{array}$} & \multicolumn{7}{|c|}{ Composition (wt.\%) } \\
\cline { 2 - 8 } & $\mathrm{Ti}$ & $\mathrm{Cr}$ & $\mathrm{Fe}$ & $\mathrm{Co}$ & $\mathrm{Ni}$ & $\mathrm{Nb}$ & $\mathrm{Mo}$ \\
\hline 1 & 0.68 & 21.67 & 24.97 & 15.72 & 35.76 & 0.56 & 0.64 \\
& \pm & \pm & \pm & \pm & \pm & \pm & \pm \\
& 0.04 & 0.14 & 0.19 & 0.15 & 0.15 & 0.1 & 0.05 \\
\hline 2 & 1.99 & 20.43 & 21.4 & 14.96 & 38.18 & 2.28 & 0.76 \\
& \pm & \pm & \pm & \pm & \pm & \pm & \pm \\
& 0.62 & 1.86 & 1.83 & 0.16 & 2.77 & 0.74 & 0.28 \\
\hline 3 & 16.74 & 7.24 & 6.46 & 3.93 & 9.7 & 54.7 & 1.23 \\
& \pm & \pm & \pm & \pm & \pm & \pm & \pm \\
& 0.22 & 0.18 & 0.35 & 0.4 & 0.56 & 1.23 & 0.08 \\
\hline
\end{tabular}

(b)

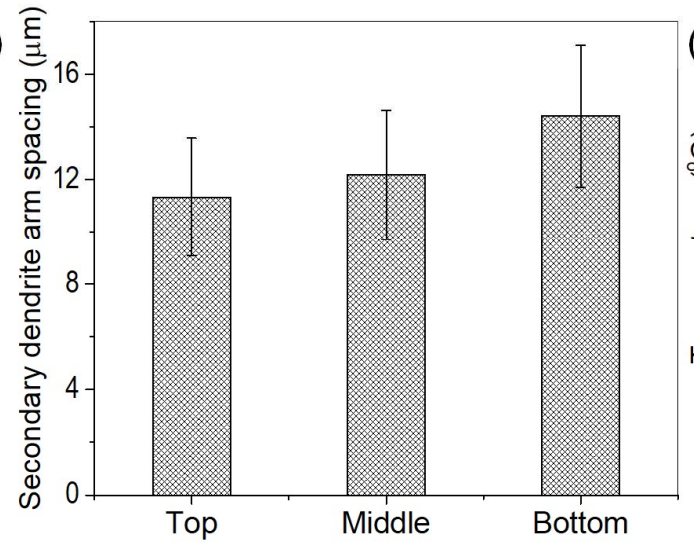

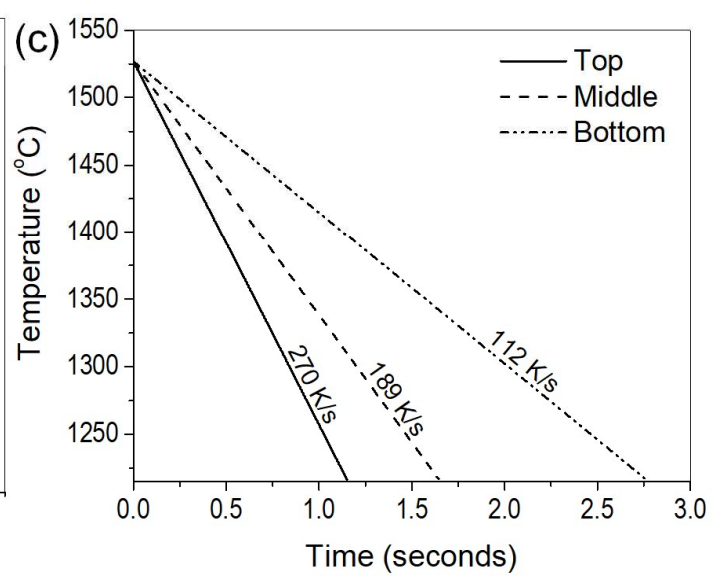

Figure 6. (a) SE-SEM micrograph showing the etched microstructure from the top portion of the sample with the secondary dendrites and the composition of points 1,2 and 3 measured using EDS as well as (b) SDAS calculated from the etched microstructure and (c) cooling rate calculated using the SDAS from different locations of the sample. 
The temperature $v s$. solid fraction curves obtained using DICTRA simulation for different locations shown in Figure 7(a) are compared with the prediction using the Scheil modeling and equilibrium calculations for the alloy containing $26 \mathrm{wt} . \%$ P91 with the composition listed in Table 1 . The solidus temperature varies significantly as the calculation method varies, mainly because of the difference in cooling rate assumed for different calculations. The cooling rate assumed in equilibrium calculation is the least with complete diffusion in both solid and liquid during solidification, due to which the solidus temperature is the highest amongst the different calculation methods. On the other hand, the Scheil model shows the lowest solidus temperature since it assumes a faster cooling rate with complete diffusion in the liquid and negligible diffusion in the solid. The solidus temperatures calculated using the one-dimensional DICTRA simulations are in between the equilibrium and Scheil calculations since the cooling rate is intermediate. Moreover, it could be seen that the solidus temperature increases from the top to bottom sections since the cooling rate increases. The solidification cracking susceptibility, which is the maximum in the slope of the temperature $v$ s. fraction of solid curve $\left(d T / d f_{s}^{0.5}\right)$ obtained using the DICTRA simulations as per the Kou criterion from various sample locations shown in Figure 7(b). The cracking susceptibility is the highest in the top portion of the sample with the highest cooling rate. Solidification cracking susceptibility decreases as the cooling rate decreases in the middle and bottom portions. The calculated solidification cracking susceptibility also correlates well with the cracking behavior characterized from different sample portions (Figure 2).
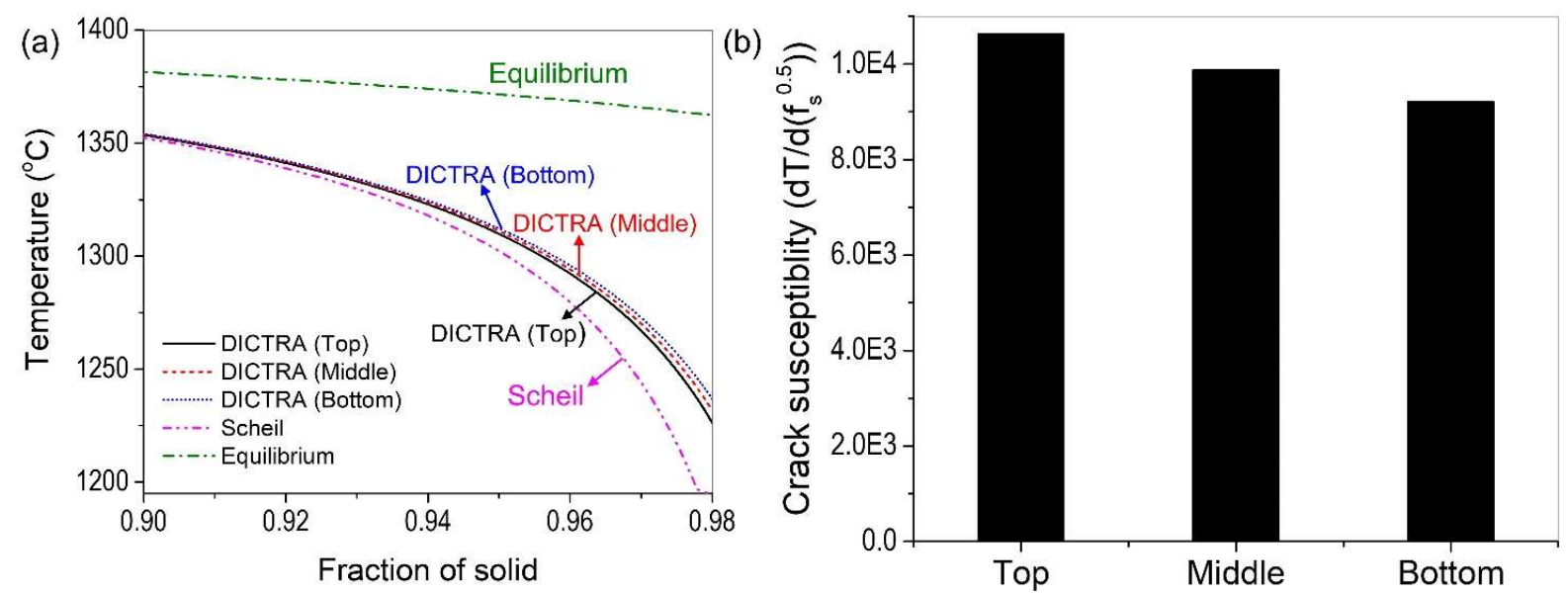

Figure 7. (a) Temperature vs. fraction of solid curves obtained using equilibrium, DICTRA and Scheil calculations at the end of solidification showing the difference in solidus temperatures at $\sim 98 \%$ solid fraction and (b) solidification cracking susceptibility calculated from different locations of the sample using the Kou criterion coupled with DICTRA calculations.

\section{Discussion}

From the above-mentioned results, it is evident that the solidification cracking susceptibility is highly location-specific for the $26 \mathrm{wt} . \%$ P91 sample fabricated using WAAM. It is also clear that the cooling rate plays a major role in inducing the location-specific cracking behavior since the top portion with the highest cooling rate had the longest crack. In addition, a difference in the extent of segregation of minor alloying elements such as $\mathrm{Nb}$ and $\mathrm{Cu}$ was also observed in different portions of the sample. However, the role of segregation on the solidification behavior needs to be probed further to identify their role in the location-specific cracking behavior. Therefore, the composition from several points within and around the cracks was measured using EDS from different sample locations and used as input for Scheil simulations. The solidification range calculated for each point from different locations is shown in Figure 8. From these EDS measurements it was observed that there is a varying degree of enrichment of $\mathrm{Nb}$ and $\mathrm{Cu}$ compared to the nominal composition of these elements for $26 \mathrm{wt}$ \% P91 graded alloy as listed in Table 1. In 
comparison with the top and middle part, the bottom region has the lowest enrichment of $\mathrm{Nb}$ (nearly $2.5 \mathrm{wt} . \%$ ) and $\mathrm{Cu}(\sim 0.4 \mathrm{wt} . \%)$, along with a lower solidification range, i.e., temperature difference between liquidus and solidus. However, in the top and middle regions, the enrichment of $\mathrm{Cu}$ and $\mathrm{Nb}$ rises rapidly. The composition of $\mathrm{Cu}$ was found to be up to $87 \mathrm{wt} . \%$ in both the regions, while the extent of enrichment of $\mathrm{Nb}$ is lesser in the Top region ( $27 \mathrm{wt} . \%)$ in comparison with the middle region ( $56 \mathrm{wt} . \%)$, which correlated well with the composition maps for $\mathrm{Nb}$ from these regions. Moreover, it can be observed that the enrichment of $\mathrm{Nb}$ and $\mathrm{Cu}$ are likely to increase the solidification range. The increase in solidification range due to the increase in $\mathrm{Nb}$ content is more pronounced than the segregation of $\mathrm{Cu}$. As the $\mathrm{Nb}$ content reaches close to $60 \mathrm{wt}$ \%, the solidification range is as high as $1133 \mathrm{~K}$, while as the $\mathrm{Cu}$ content becomes higher, the solidification range is up to $681 \mathrm{~K}$. It is to be noted that the effect of other minor alloying elements such as Mo and Ti also play a role, although not as noticeable as $\mathrm{Nb}$. For instance, in the top region, a wide solidification range $(848 \mathrm{~K})$ was observed at a point where the $\mathrm{Cu}$ content was intermediate ( $30 \mathrm{wt} . \%)$ in comparison with the maximum enrichment while the $\mathrm{Nb}$ and Mo content was almost equal ( $2.5 \mathrm{wt}$. \%). It was also observed that Mo affects the solidification range significantly if it is equal to the composition of $\mathrm{Nb}$ along with higher $\mathrm{Cu}$ content. This proves that the effect of $\mathrm{Mo}$ is not as significant as $\mathrm{Nb}$ in affecting the solidification range.

A higher solidification range is known to affect the printability during AM by inducing solidification cracks. According to the generalized theory for cracking proposed by Borland [38], solidification occurs in several stages. In the initial stage, the liquid and solid phases are continuous to accommodate relative movement. Further, the dendrites grow and get interlocked while the liquid can move, thus, healing the cracks that form in this stage. Towards the end of solidification, the dendrites are completely grown and obstruct the liquid flow into the interdendritic regions to compensate for the shrinkage and strain. Hence, if an external stress is applied that exceeds the tolerance limit, cracking occurs, which cannot be backfilled by the liquid. If the solidification range is relatively higher, the number of interlocked dendrites that form at the later stage of solidification is higher, and hence, there will be more hindrance for the liquid to get backfilled [39]. The reduction of solidus temperature leading to an increase in the solidification range due to the segregation of $\mathrm{Cu}$ and $\mathrm{Nb}$ can be attributed to the formation of solidification cracks in the $26 \mathrm{wt}$. \% P91 build. Though, copper is added for solid solution strengthening effects, it is known to segregate in grain boundaries leading to reduction in hot malleability and creep ductility in Ni-base superalloys [40]. Long term diffusion annealing is known eliminate the segregation of copper. However, in the WAAM process, since sufficient time is not provided for the copper to dissolve and redistribute into the matrix owing to the faster cooling rate, the segregation is expected to be observed. In addition, $\mathrm{Nb}$ is known to segregate in the intergranular regions in $\mathrm{Ni}$-base superalloys with moderately high $\mathrm{Nb}$ content (> $1 \mathrm{wt} . \%)$. Hence, segregation of $\mathrm{Cu}$ and $\mathrm{Nb}$ is inevitable due to their ability to get enriched in grain boundaries and intergranular regions, respectively. 

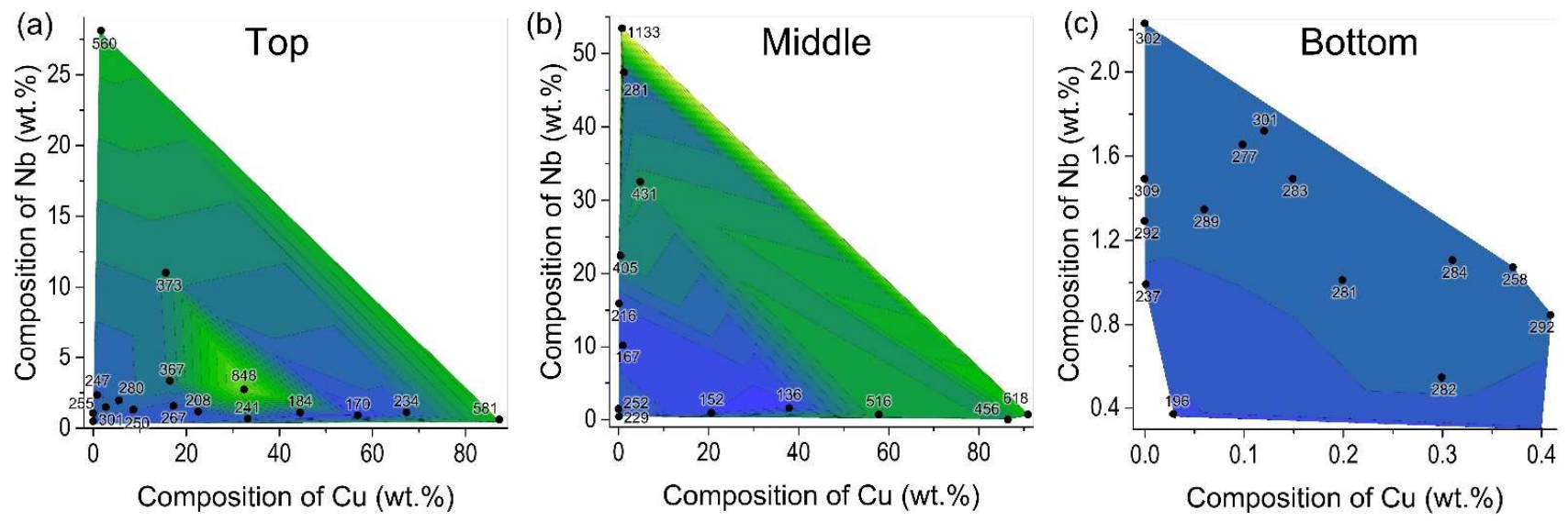

Solidification range $(\mathrm{K})$

$100 \quad 205 \quad 310 \quad 415520 \quad 62573083594010451150$

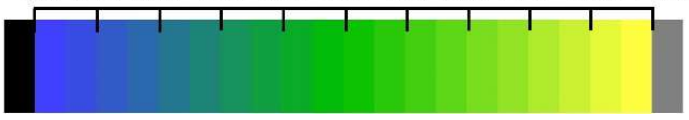

Figure 8. Solidification ranges obtained using Scheil simulations as a function of $\mathrm{Nb}$ and $\mathrm{Cu}$ content from different points at (a) bottom, (b) middle and (c) top regions of the 26 wt.\% P91 build.

To mitigate location-specific solidification cracking in fabricating graded alloy from P91 to Inconel 740H using WAAM, the following solutions are suggested to obtain a crackfree build. Solidification characteristics such as the solidification range as well as the overall solidification cracking susceptibility should be considered as the primary factors when evaluating printability. Although alloy entropy may help to stabilize the microstructure, it does not have a direct influence on preventing crack formation, and thus should be considered with other design factors during the interlayer design for joining P91 steel with $740 \mathrm{H}$ superalloy. Figure 9 represents the overall solidification cracking susceptibility using the Kou criterion and the freezing range computed using the outputs from Scheil calculations performed for the mixed compositions between $\mathrm{P} 91$ steel and $740 \mathrm{H}$ superalloy in steps of $1 \mathrm{wt} . \%$. In this case, the maximum slope was calculated from the temperature vs. fraction of solid curve obtained from Scheil simulation for each alloy composition to apply the Kou criterion. From this plot, evidently, the overall solidification cracking susceptibility is highest around $26 \mathrm{wt} . \%$ P91. Moreover, there is an abrupt increase in the freezing range close to that composition. This proves that even though the calculated entropy for $26 \mathrm{wt} . \%$ P91 may be the highest, the solidification characteristics of this alloy are not conducive to being fabricated using WAAM. Thus, a careful analysis of the important attributes during solidification, such as freezing range and overall solidification cracking susceptibility, needs to be accounted for during the design of interlayers for joining dissimilar materials using AM. It is to be noted that, though segregation is one of the major factors that affect the cracking behavior, the overall solidification range is also equally important. The segregation behavior along with the freezing range will influence the solidification cracking susceptibility. From Figure 9, it is clearly evident that the freezing range of pure Inconel $740 \mathrm{H}$ is much lower than the $26 \mathrm{wt} . \%$ P91 graded alloy. It is well known that the smaller the freezing range, the lower will be the solidification cracking susceptibility. Hence, in Inconel $740 \mathrm{H}$, though the $\mathrm{Nb}$ segregates and forms Laves phase in the interdendritic region (as observed from our previous work), the lower freezing range does not allow it to form cracks. Hence, it is clearly evident that a complex interplay between the solidification range and segregation behavior influences the solidification cracking susceptibility. 


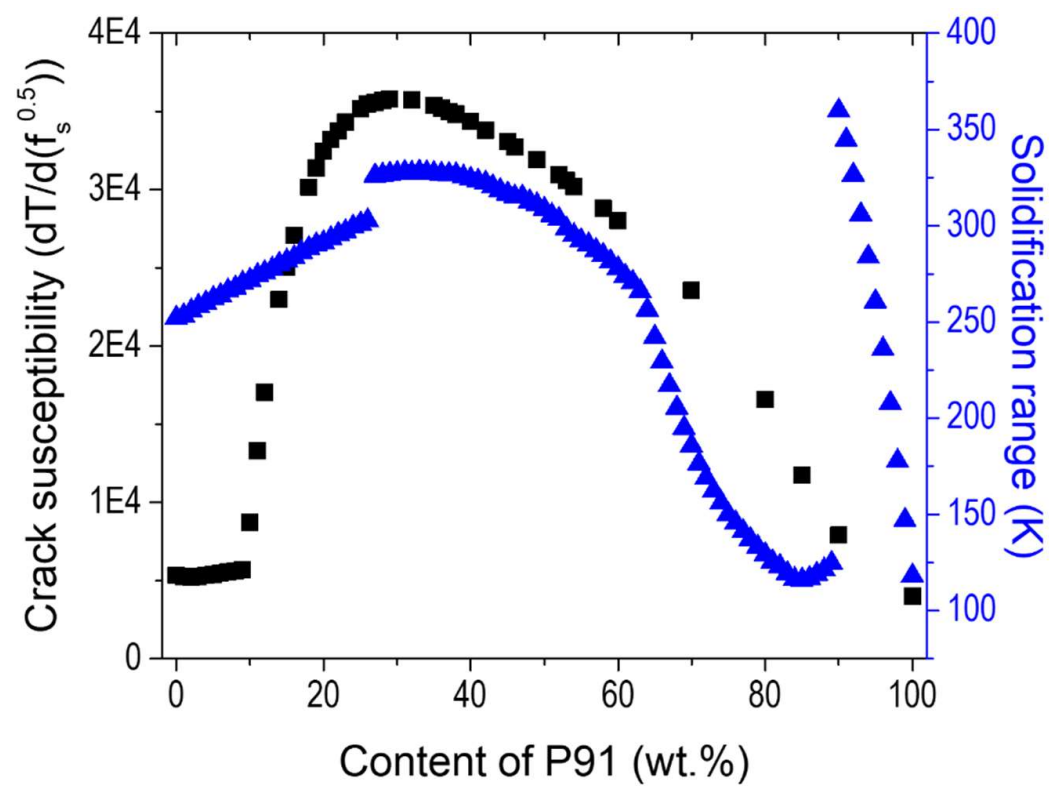

Figure 9. Overall solidification cracking susceptibility determined using Kou criterion and freezing range calculated using Scheil simulations for different mixed compositions between P91 steel and 740H superalloy.

Another possible method to minimize the formation of cracks in $26 \mathrm{wt} . \%$ P91 alloy is to alter the printing strategy. During the fabrication using the WAAM technique, the interpass temperature was maintained as $175^{\circ} \mathrm{C}$, i.e., before the deposition of every layer, the previous layer was cooled to $175^{\circ} \mathrm{C}$. The interpass temperature directly influences the solidification rate of each new deposited layer. A low interpass temperature will result in a high cooling rate along with the inability to accommodate the internal stresses that form during solidification, leading to the formation of solidification cracks [41]. Therefore, if the interpass temperature is increased (i.e., if the interpass time is decreased) during the deposition of each layer, the cooling rate decreases which will reduce the solidification cracking. In this case, a longer cooling time will give enough duration for the strains to be accommodated to avoid cracking. In addition, increasing the cooling time will provide sufficient time for the minor alloying elements such as copper to re-distribute into the matrix and avoid enrichment in grain boundaries causing intergranular solidification cracks. However, the dilution between the subsequent layers that will affect the build height will increase if the interpass temperature increases. Hence, an optimum interpass temperature that does not allow considerable dilution between the layers needs to be identified for obtaining crack-free builds without losing the dimensional accuracy.

\section{Conclusions}

In this work, location-specific solidification cracking susceptibility has been investigated using an ICME approach for an alloy fabricated using WAAM with mixed composition between $\mathrm{P} 91$ steel and $740 \mathrm{H}$ superalloy for the first time. Based on the analysis presented above, the significant outcomes from this study can be summarized as follows.

- The total entropy calculated using the CALPHAD method and the configurational entropy was the highest for $26 \mathrm{wt} . \%$ P91 alloy amongst the mixed compositions between P91 steel and 740H superalloy. It was fabricated using WAAM with a twinwire feeder for maintaining the required composition and the interpass temperature was maintained to be $175^{\circ} \mathrm{C}$. This alloy was designed to act as a potential interlayer for joining P91 steel and 740H superalloy using AM.

- The 26 wt.\% P91 alloy has a single-phase FCC structure with intergranular cracks of varying lengths in the top and middle portions of the build and no cracks in the bottom region. The extent of segregation of minor alloying elements such as $\mathrm{Nb}$ and $\mathrm{Cu}$ 
were different within/around the cracks in the top and middle portions of the sample.

- The cooling rate decreased and the SDAS increased from the top to bottom portion of the build. The solidification cracking susceptibility deduced using the Kou criterion coupled with DICTRA simulations was the highest for the Top and lowest for the Bottom region. The calculated solidus temperatures using DICTRA from different regions were intermediate between the Scheil and equilibrium calculations.

- The enrichment of $\mathrm{Cu}(\sim 87 \mathrm{wt} . \%)$ and $\mathrm{Nb}(\sim 27$ to $56 \mathrm{wt} . \%)$ was more pronounced in the top and middle regions in comparison with the bottom part of the sample leading to suppression of the solidus temperature and increase of the solidification range which in turn increased the solidification cracking susceptibility.

- The overall solidification cracking susceptibility was highest for the $26 \mathrm{wt} . \%$ P91 amongst the mixed composition between P91 steel and 740H superalloy and an abrupt increase in freezing range was observed at that composition. In order to mitigate solidification cracking, a different alloy with a lower freezing range as well as solidification cracking susceptibility needs to be chosen and the printing strategy needs to be altered by increasing the interpass temperature to decrease the cooling rate. The choice of alloy composition as well as the deposition strategy is important for achieving a crack-free build using WAAM.

\begin{abstract}
Author Contributions: Conceptualization, W.X.; methodology, W.X.; software, N.S. and X.W.; validation, S.S., N.S. and X.W.; formal analysis, S.S., N.S. and X.W.; investigation, S.S., N.S., X.W., M.K. and W.X.; resources, W.X. and M.K.; data curation, S.S., N.S. and X.W.; writing-original draft preparation, S.S.; writing - review and editing, S.S., N.S., X.W., M.K. and W.X.; visualization, S.S., N.S. and X.W.; supervision, W.X.; project administration, W.X.; funding acquisition, W.X and M.K. All authors have read and agreed to the published version of the manuscript.
\end{abstract}

Funding: This research was funded by National Energy Technology Laboratory, Department of Energy, United States, grant number DE-FE0031637. N.S. is supported by a NASA Space Technology Research Fellowship, Grant: 80NSSC19K1142.

Institutional Review Board Statement: Not applicable.

Informed Consent Statement: Not applicable.

Disclaimer: This report was prepared as an account of work sponsored by an agency of the United States Government. Neither the United States Government nor any agency thereof, nor any of their employees, makes any warranty, express or implied, or assumes any legal liability or responsibility for the accuracy, completeness, or usefulness of any information, apparatus, product, or process disclosed, or represents that its use would not infringe privately owned rights. Reference herein to any specific commercial product, process, or service by trade name, trademark, manufacturer, or otherwise does not necessarily constitute or imply its endorsement, recommendation, or favoring by the United States Government or any agency thereof. The views and opinions of authors expressed herein do not necessarily state or reflect those of the United States Government or any agency thereof

Acknowledgments: S.S. acknowledges Miss Lauren Wewer for her assistance in sample preparation through the Mascaro Centre for Sustainable Innovation (MCSI) summer internship program.

Conflicts of Interest: The authors declare no conflict of interest.

\title{
References
}

1. Abd El-Azim, M.E.; Ibrahim, O.H.; El-Desoky, O.E. Long term creep behaviour of welded joints of P91 steel at $650{ }^{\circ}$ C. Mater. Sci. Eng. A 2013, 560, 678-684, doi:10.1016/J.MSEA.2012.10.013.

2. Barbadillo, J.J. De; Baker, B.A.; Virginia, W. Microstructure stability of Alloy $740 \mathrm{H}$ and its effect on material properties. In Proceedings of the Proceedings of the ASME Symposium on Elevated Temperature Application 
of Materials for Fossil, Nuclear and Petrochemical Industries; 2014; pp. 1-13.

3. George, E.P.; Raabe, D.; Ritchie, R.O. High-entropy alloys. Nat. Rev. Mater. 2019, 4, 515-534, doi:10.1038/s41578019-0121-4.

4. Tsai, M.-H.; Yeh, J.-W. High-Entropy Alloys: A Critical Review. http://mc.manuscriptcentral.com/tmrl 2014, 2, 107123, doi:10.1080/21663831.2014.912690.

5. Miracle, D.B.; Senkov, O.N. A critical review of high entropy alloys and related concepts. Acta Mater. 2017, 122, 448-511, doi:10.1016/J.ACTAMAT.2016.08.081.

6. Zhang, Y.; Zuo, T.T.; Tang, Z.; Gao, M.C.; Dahmen, K.A.; Liaw, P.K.; Lu, Z.P. Microstructures and properties of high-entropy alloys. Prog. Mater. Sci. 2014, 61, 1-93, doi:10.1016/J.PMATSCI.2013.10.001.

7. Gorsse, S.; Hutchinson, C.; Gouné, M.; Banerjee, R. Additive manufacturing of metals: a brief review of the characteristic microstructures and properties of steels, Ti-6Al-4V and high-entropy alloys. Sci. Technol. Adv. Mater. 2017, 18, 584-610, doi:10.1080/14686996.2017.1361305.

8. Imran, M.K.; Masood, S.H.; Brandt, M.; Bhattacharya, S.; Mazumder, J. Direct metal deposition (DMD) of H13 tool steel on copper alloy substrate: Evaluation of mechanical properties. Mater. Sci. Eng. A 2011, 528, 3342-3349, doi:10.1016/j.msea.2010.12.099.

9. Domack, M.S.; Baughman, J.M. Development of nickel-titanium graded composition components. Rapid Prototyp. J. 2005, 11, 41-51, doi:10.1108/13552540510573383.

10. Sahasrabudhe, H.; Harrison, R.; Carpenter, C.; Bandyopadhyay, A. Stainless steel to titanium bimetallic structure using LENSTM. Addit. Manuf. 2015, 5, 1-8, doi:10.1016/j.addma.2014.10.002.

11. Zhou, X.; Tian, Q.; Du, Y.; Zhang, Y.; Bai, X.; Zhang, Y.; Zhang, H.; Zhang, C.; Yuan, Y. Investigation of the effect of torch tilt and external magnetic field on arc during overlapping deposition of wire arc additive manufacturing. Rapid Prototyp. J. 2021, 27, 24-36, doi:10.1108/RPJ-03-2020-0047/FULL/XML.

12. Tang, S.; Wang, G.; Song, H.; Li, R.; Zhang, H. A novel method of bead modeling and control for wire and arc additive manufacturing. Rapid Prototyp. J. 2021, 27, 311-320, doi:10.1108/RPJ-05-2020-0097/FULL/XML.

13. Fang, X.; Ren, C.; Zhang, L.; Wang, C.; Huang, K.; Lu, B. A model of bead size based on the dynamic response of CMT-based wire and arc additive manufacturing process parameters. Rapid Prototyp. J. 2021, 27, 741-753, doi:10.1108/RPJ-03-2020-0051/FULL/XML.

14. Kulkarni, J.D.; Goka, S.B.; Parchuri, P.K.; Yamamoto, H.; Ito, K.; Simhambhatla, S. Microstructure evolution along build direction for thin-wall components fabricated with wire-direct energy deposition. Rapid Prototyp. J. 2021, 27, 1289-1301, doi:10.1108/RPJ-04-2020-0085/FULL/XML.

15. Chen, X.; Fu, Y.; Kong, F.; Li, R.; Xiao, Y.; Hu, J.; Zhang, H. An in-process multi-feature data fusion nondestructive testing approach for wire arc additive manufacturing. Rapid Prototyp. J. 2021, doi:10.1108/RPJ-022021-0034/FULL/XML. 
16. Zhao, Y.; Li, K.; Gargani, M.; Xiong, W. A comparative analysis of Inconel 718 made by additive manufacturing and suction casting: Microstructure evolution in homogenization. Addit. Manuf. 2020, 36, 101404, doi:10.1016/j.addma.2020.101404.

17. Sargent, N.; Jones, M.; Otis, R.; Shapiro, A.A.; Delplanque, J.-P.; Xiong, W. Integration of Processing and Microstructure Models for Non-Equilibrium Solidification in Additive Manufacturing. Met. 2021, Vol. 11, Page 570 2021, 11, 570, doi:10.3390/MET11040570.

18. Jimenez, X.; Dong, W.; Paul, S.; Klecka, M.A.; To, A.C. Residual Stress Modeling with Phase Transformation for Wire Arc Additive Manufacturing of B91 Steel. JOM 2020, 72, 4178-4186, doi:10.1007/s11837-020-04424-w.

19. Kou, S. A criterion for cracking during solidification. Acta Mater. 2015, 88, 366-374, doi:10.1016/J.ACTAMAT.2015.01.034.

20. Kou, S. Solidification and liquation cracking issues in welding. JOM 2003, 55, 37-42, doi:10.1007/S11837-0030137-4.

21. Eskin, D.G.; Suyitno; Katgerman, L. Mechanical properties in the semi-solid state and hot tearing of aluminium alloys. Prog. Mater. Sci. 2004, 49, 629-711, doi:10.1016/S0079-6425(03)00037-9.

22. Prokhorov, N.N. Resistance to hot tearing of cast metals during solidification. Russ. Cast. Prod. 1962, 2, $172-175$.

23. Feurer, U. Mathematical model by the hot cracking tendency of binary aluminum alloys. Giessereiforschung 1976, 28, 75-80, doi:10.1007/BF03339110.

24. Nasresfahani, M.R.; Niroumand, B. A New Criterion for Prediction of Hot Tearing Susceptibility of Cast Alloys. Metall. Mater. Trans. A 2014459 2014, 45, 3699-3702, doi:10.1007/S11661-014-2341-Y.

25. Rappaz, M.; Drezet, J.-M.; Gremaud, M. A new hot-tearing criterion. Metall. Mater. Trans. A 1999302 1999, 30 , 449-455, doi:10.1007/S11661-999-0334-Z.

26. Ploshikhin, V.; Prikhodovsky, A.; Makhutin, M.; Ilin, A.; Zoch, H.-W. Integrated Mechanical-Metallurgical Approach to Modeling of Solidification Cracking in Welds. In Hot Cracking Phenomena in Welds; Böllinghaus, T., Herold, H., Eds.; Springer Berlin Heidelberg: Berlin, Heidelberg, 2005; pp. 223-244 ISBN 978-3-540-27460-5.

27. Malekshahi Beiranvand, Z.; Malek Ghaini, F.; Naffakh Moosavy, H.; Sheikhi, M.; Torkamany, M.J. An Analytical Model for Prediction of Solidification Cracking Susceptibility in Aluminum Alloys Taking into Account the Effect of Solidification Rate. Metall. Mater. Trans. A 2019506 2019, 50, 2835-2846, doi:10.1007/S11661-019-051717.

28. Kou, S. A Simple Index for Predicting the Susceptibility to Solidification Cracking. Weld. J. 2015, 94, 374-388.

29. Chen, Q.; Sundman, B. Computation of Partial Equilibrium Solidification with Complete Interstitial and Negligible Substitutional Solute Back Diffusion. Mater. Trans. 2002, 43, 551-559, doi:10.2320/matertrans.43.551.

30. Sargent, N.; Jones, M.; Otis, R.; Shapiro, A.A.; Delplanque, J.P.; Xiong, W. Integration of processing and microstructure models for non-equilibrium solidification in additive manufacturing. Metals (Basel). 2021, 11, 1- 
12, doi:10.3390/met11040570.

31. Giorjao, R.; Sutton, B.; Ramirez, A. New Composition Based Technique for Solidification Cracking Resistance Evaluation. Metall. Mater. Trans. A 2021526 2021, 52, 2512-2521, doi:10.1007/S11661-021-06244-2.

32. Cao, Y.; Wei, H.L.; Yang, T.; Liu, T.T.; Liao, W.H. Printability assessment with porosity and solidification cracking susceptibilities for a high strength aluminum alloy during laser powder bed fusion. Addit. Manuf. 2021, 46, 102103, doi:10.1016/J.ADDMA.2021.102103.

33. Hyer, H.; Zhou, L.; Mehta, A.; Park, S.; Huynh, T.; Song, S.; Bai, Y.; Cho, K.; McWilliams, B.; Sohn, Y. Composition-dependent solidification cracking of aluminum-silicon alloys during laser powder bed fusion. Acta Mater. 2021, 208, 116698, doi:10.1016/J.ACTAMAT.2021.116698.

34. Dovgyy, B.; Simonelli, M.; Pham, M.-S. Alloy design against the solidification cracking in fusion additive manufacturing: an application to a FeCrAl alloy. http://mc.manuscriptcentral.com/tmrl 2021, 9, 350-357, doi:10.1080/21663831.2021.1922945.

35. José Tinoco; Hasse Fredriksson Solidification of a Modified Inconel 625 Alloy under Different Cooling Rates. High Temp. Mater. Process. 2004, 23, 13-24, doi:10.1515/HTMP.2004.23.1.13.

36. Calcagnotto, M.; Ponge, D.; Demir, E.; Raabe, D. Orientation gradients and geometrically necessary dislocations in ultrafine grained dual-phase steels studied by 2D and 3D EBSD. Mater. Sci. Eng. A 2010, 527, 2738-2746, doi:10.1016/j.msea.2010.01.004.

37. Sridar, S.; Zhao, Y.; Xiong, W. Cyclic re-austenitization of copper-bearing high-strength low-alloy steels fabricated by laser powder bed fusion. Mater. Charact. 2020, 166, 110437, doi:10.1016/j.matchar.2020.110437.

38. Borland, J.; Younger, R. Some aspects of cracking in welded Cr-Ni austenitic steels. Br. Weld. J. 1960, 7, $22-59$.

39. Yan, F.; Yan, J.; Linder, D. Understanding Hot Cracking of Steels during Rapid Solidification: An ICME Approach. Mater. Proc. 2021, Vol. 3, Page 30 2021, 3, 30, doi:10.3390/IEC2M-09254.

40. Jena, A.K.; Chaturvedi, M.C. The role of alloying elements in the design of nickel-base superalloys. J. Mater. Sci. 19841910 1984, 19, 3121-3139, doi:10.1007/BF00549796.

41. Gokuldoss, P.K.; Kolla, S.; Eckert, J. Additive Manufacturing Processes: Selective Laser Melting, Electron Beam Melting and Binder Jetting-Selection Guidelines. Mater. 2017, Vol. 10, Page 672 2017, 10, 672, doi:10.3390/MA10060672. 